\title{
MODULATION OF LATERAL GENICULATE NUCLEUS CELL RESPONSIVENESS BY VISUAL ACTIVATION OF THE CORTICOGENICULATE PATHWAY ${ }^{1}$
}

\author{
RICHARD T. MARROCCO, ${ }^{2}$ J. W. McCLURKIN, AND R. A. YOUNG \\ Institute of Neuroscience, University of Oregon, Eugene, Oregon 97403 \\ Received April 17, 1981; Revised October 14, 1981; Accepted October 18, 1981
}

\begin{abstract}
A radial grating stimulus was used to assess the effect of stimulation of the region beyond the classical surround of monkey lateral geniculate nucleus (LGN) receptive fields. The effect was measured by the differences in the responsiveness of the LGN cell center to small flashing spots between two conditions: (1) grating stationary or (2) grating rotating. The grating was present only in regions beyond the classical center and surround.

The rotating grating produced changes in the flash-evoked spike response but not in the spontaneous activity in about half of the $\mathrm{X}$ cells and all of the $\mathrm{Y}$ cells. The direction of the effect was independent of the sign of the receptive field center. In a control experiment, cryogenic blockade of striate cortex reversed the effect in all cells tested. The grating effect was still present for cells having fields in that part of visual space beyond the region represented by the cooled cortical area. The effect was not a result of activation of classical extra-receptive field influences, since cells showing the effect did not exhibit shift or periphery effects or outer disinhibitory surrounds. The effect was not seen in recordings from intrageniculate retinal axons. We conclude that the radial grating effects LGN cell responsivity by activation of the corticogeniculate pathway.
\end{abstract}

Perhaps one of the most ubiquitous yet least well understood aspects of sensory systems is the feedback pathway. The size of these pathways varies a great deal. The olivocochlear bundle in cats is thought to contain about 500 fibers (Spoendlin, 1966); the retinopetal pathway from the isthmo-optic nucleus in birds contains about 10,000 fibers (Cowan and Powell, 1963). In each case, the feedback pathway is smaller in number of fibers compared to the number in the afferent pathway that it may modulate. Of more interest to mammalian vision is the corticogeniculate (CG) feedback pathway. Although difficult to measure, a reasonable estimate based on current anatomy (Lund et al., 1975) suggests that the CG pathway in monkey probably contains between 100,000 and 200,000 neurons. Thus, it would appear that the size of this pathway is a substantial fraction of the million or so fibers that constitute the geniculocortical radiation.

Several attempts have been made to elucidate the

\footnotetext{
' This research was supported by National Institutes of Health Grants EY 01286-05 and 5T32 GMO 7257. We thank Z. H. H. Farooqi for technical assistance and Drs. A. Fiorentini and F. M. deMonasterio for critical review of the manuscript.

${ }^{2}$ To whom correspondence should be addressed at Department of Psychology, University of Oregon, Eugene, OR 97403.
}

physiological function of this pathway. Vastola (1967) used cathodal block polarization of cat visual cortex while recording from lateral geniculate nucleus (LGN) cells. The effect of $\mathrm{CG}$ feedback was assessed as a change in LGN cell activity that had been raised artificially by repetitive stimulation of the optic tract. He found a predominantly excitatory feedback effect on LGN cells. However, cathodal stimulation in cortex produces some repetitive firing in geniculate terminals and it is difficult to parcel out the effects of antidromic activation of LGN cells from orthodromic driving by the CG pathway.

Cryogenic blockade of the visual cortex can eliminate activity in layer 6 of visual cortex, in which the somata of the CG pathway are located (Gilbert, 1977; Gilbert and Kelly, 1975; Lund et al., 1975). This approach has been used to compare spontaneous and light-driven LGN activity rates before and after cortical cooling, but there is some dispute as to the direction of the effects. The effect of the CG pathway was described as clearly excitatory (Hull, 1968; Schmielau and Singer, 1977), subtly excitatory (Baker and Malpeli, 1977; Kalil and Chase, 1970), absent (Richard et al., 1975), or clearly inhibitory (Hull, 1968). Geisert et al. (1981) have described mixed excitatory/inhibitory effects in the same cells. Estimates of the number of cells affected in these studies ranged from 
$86 \%$ to none. The cooling technique used to block the cortex, however, is cumbersome and time consuming. We report here a new technique for visually activating the CG pathway. Our results suggest that about half of all LGN cells tested are affected by our procedures and, in most cases, the effect is inhibitory. A brief report of these results has appeared elsewhere (Marrocco et al., 1979).

\section{Materials and Methods}

Three cynomolgus macaque monkeys were implanted surgically with plastic recording chambers under Nembutal anesthesia. A chamber was placed over trephine holes in the skull overlying each lateral geniculate nucleus. In addition, bolts were secured to the skull with dental acrylic, which served to hold the head painlessly during subsequent recording sessions. Bipolar, concentric stimulating electrodes were implanted bilaterally in the optic chiasm at depths such that multiunit activity to light was maximal. All scalp wounds were closed and the animals were allowed 2 weeks for recovery, during which periodic checks were made of eating habits, weight, and activity. Antibiotics were administered as necessary to control local infection.

Conventional procedures (Marrocco, 1976) were used to obtain extracellular recordings from cells in the LGN. Animals were medicated initially with ketamine and placed in the stereotaxic instrument. A Flaxedil/ $d$-tubocurarine mixture was infused intravenously to prevent eye movements. Anesthesia was maintained during the experiment by artificial respiration with $70 \% \mathrm{~N}_{2} \mathrm{O}, 30 \%$ $\mathrm{O}_{2}$. Vital functions (EKG, EEG, $\mathrm{CO}_{2}$, and temperature) were monitored continuously. Tungsten microelectrodes coated with Epoxylite were used for these experiments. Spike potentials were fed into a window discriminator, whose output of standardized pulses was fed to a Nicolet 1072 signal averager. We constructed response histograms from 32 identical stimuli and produced hard copies with an X-Y plotter. Histograms were smoothed with an $\mathrm{RC}$ network having a 40-msec (real) time constant.

In three experiments, we recorded from intrageniculate retinal axons. We identified these by (1) lack of an inflection point on the rising phase of the potential (i.e., no A-B break; see Bishop et al., 1962); (2) short duration, primarily monophasic waveform; and (3) faithful following $(<100-\mu \mathrm{sec}$ jitter) of $250-\mathrm{Hz}$ optic chiasm shocks.

The animal's eyes were covered with plano contact lenses having $3.2-\mathrm{mm}^{2}$ artificial pupils. The contact lenses were cushioned with hydroxypropyl methylcellulose. A cycloplegic paralyzed accommodation and phenylephrine hydrochloride produced mydriasis. Supplementary lenses, as determined by streak retinoscopy, focused the eyes on a tangent screen $114 \mathrm{~cm}$ distant. The eyes were irrigated every $4 \mathrm{hr}$ with normal saline during the recording sessions.

Several dependent variables were measured for all cells. First, the spectral type of the cell was determined. Spectral responses were recorded to a series of small, near-monochromatic spots of equal energy on neutral and chromatic backgrounds. Spots and annuli were used to determine center and surround dimensions. The cells also were classified by the regions of the spectrum giving the maximum responses and the position of the neutral point, if present. Second, the spatial linearity type was determined. Responses to a luminance-modulated counterphasing sine wave grating of variable contrast and spatial frequency was used to test for spatial linearity. We routinely used contrasts (between 20 and $50 \%$ ) which modulated the discharge rate by about 20 impulses/sec. The spatial frequency of the grating was chosen so as to be about one octave above the spatial frequency to which the cell was most sensitive. Cells showing "null positions" to at least one position of the grating on the receptive field presumably had linear summation and were classified as X cells. Those showing frequency doubling but no null positions to all grating positions presumably had nonlinear summation and were classified as Y cells (e.g., see Enroth-Cugell and Robson, 1966). Finally, we measured shock latency to stimulation of the optic chiasm. The position of the receptive field with respect to the fovea also was recorded for each cell.

Rationale. The receptive field centers of LGN cells within the central $10^{\circ}$ of gaze have median areas of approximately $0.04 \mathrm{deg}^{2}$ (Wiesel and Hubel, 1966), while the central areas of layer 6 cortical cells average about 4 $\mathrm{deg}^{2}$ at the same eccentricity (Hubel and Wiesel, 1968; Schiller et al., 1976). Several authors (Gilbert, 1977; Harvey, 1978) have shown that CG cells in layer 6 have receptive field properties that are similar in every respect to non-CG layer 6 cells. Therefore, CG cells have fields roughly two orders of magnitude larger than the receptive field center regions of the LGN cells to which they project. It also has been established that a strict retinotopy exists between cortical cells and the cells of the LGN contacted by those cortical cells (Hendrickson et al., 1978; Holländer and Martinez-Milan, 1975). We reasoned that a stimulus appropriate for simple or complex CG cells (e.g., moving borders of appropriate spatial frequency) but with the central region masked should excite cortical cells while sparing the LGN cell whose receptive field is presumably located within the central disk region of the stimulus. Since the spatial preferences of the cortical cells mediating the presumed feedback were unknown, we chose a radial grating whose vanes were of variable widths. The exact size of the central disk could be tailored to just exceed the outer dimensions of each LGN cell surround. Since we know that CG cells usually required a moving visual stimulus (e.g., Gilbert, 1977), the stationary grating itself should have little effect on the cells. Figure 1 illustrates the stimulus paradigm.

Three sets of data were collected for each cell. First, spots of light of different areas were flashed on the receptive field. The smallest spot giving the largest response was assumed to just cover the receptive field center for our test stimulus. We flashed a spot $40 \%$ smaller than this at $1.5 \log$ units above a $10 \mathrm{~cd} / \mathrm{m}^{2}$ background. Second, we repeated these test flashes in the presence of the radial grating, whose mean spaceaveraged luminance was also $1.5 \mathrm{log}$ units above the background. The grating was absent in a central area whose diameter was chosen so as not to encroach on the classical receptive field surround. The size of this surround was determined by a modified area-threshold paradigm. Annuli of various internal and external diameters were flashed on the receptive field, about a small white 

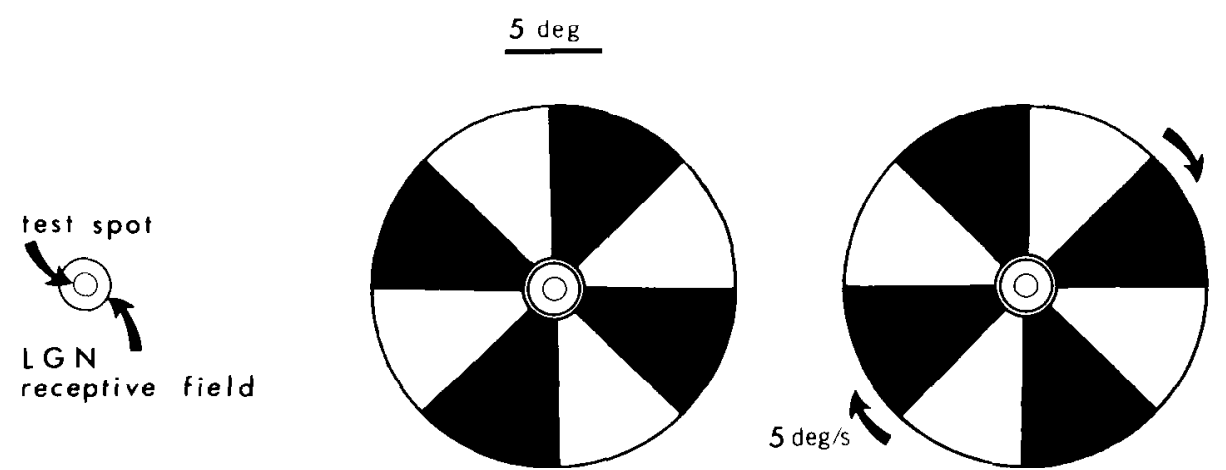

Figure 1. The stimulus paradigm. The left figure shows the size and location of the test spot within the LGN receptive field (center + surround). The middle figure shows that the actual size of the central disk varied for each cell, such that it was slightly larger than the receptive field surround. The right figure indicates the rotation of the grating. The test spot is flashed for $1 \mathrm{sec}$ in each condition. Spot luminance is $300 \mathrm{~cd} /$ $\mathrm{m}^{2}$; adapting background is $10 \mathrm{~cd} / \mathrm{m}^{2}$. The luminance of the light grating bars is 300 $\mathrm{cd} / \mathrm{m}^{2}$; that of the dark bars is $0.09 \mathrm{~cd} / \mathrm{m}^{2}$.

spot which steadily illuminated the center. The inside diameter of the smallest annulus which failed to modulate the central spot-driven activity was defined operationally as the limit of the receptive field surround. Thus, the receptive field was not subjected directly to the effects of the light and dark vanes. In the third condition, the spot was flashed while the grating was in radial motion. If feedback were present, we could presumably assess its presence by the difference in response, if any, between the responses to the spot plus stationary grating and the spot plus moving grating. This comparison eliminates stray light as a contaminant since the space-averaged luminance of the grating is invariant between these two conditions. We also used 1 log unit dimmer gratings, gratings moving at $1 \%$ sec, and gratings with unequal sectors, but the results, described below, were identical. The order in which the conditions were run was semirandom. The nondominant eye was occluded during all tests.

In four experiments, we examined the effect of cryogenic blockage of area 17 on the response properties of LGN cells. Ice water at $0.5^{\circ} \mathrm{C}$ was circulated through a chamber cemented to the skull overlying area 17 . An area of visual space approximately 1 to $4^{\circ}$ horizontally and 1 to $10^{\circ}$ vertically was cooled. A calibrated thermistor probe monitored cortical temperature at the surface of the dura in the center of the chamber. The cortex was cooled to about 2 to $3^{\circ} \mathrm{C}$ for about $3 \mathrm{~min}$, enough time to collect several averaged response histograms. The cool water then was replaced with water at $37.5^{\circ} \mathrm{C}$ to rewarm the cortical surface.

\section{Results}

Three types of effects of the moving grating on LGN cells were found in these experiments: inhibitory effects, excitatory effects, and no effect. Cells illustrating these effects can be seen in Figure 2. The top row of histograms was obtained from $a+G$ center $/-R$ surround $X$ cell in LGN layer 6. Its receptive field was about $0.09 \mathrm{deg}^{2}$ and was located $6^{\circ}$ from the fovea in the lower temporal quadrant. The sustained responses to the center test. flash alone (first column) are characteristic of spectrally opponent cells (Marrocco, 1976). The response in the presence of the stationary graling (second column) is reduced, probably due to the addition of stray light stimulation of the inhibitory surround. The addition of movement to the display (third column) dramatically reduces both the transient and maintained portions of the response.

The second row illustrates results from a $+\mathrm{R}$ center/ $-G$ surround $X$ cell in LGN layer 3. Spots alone (first column) produced an inhibition of activity at light onset followed by a transient burst at offset. The stationary grating (second column) increased the size of the off transient by $50 \%$. The moving grating (third column) increased the off transient by another $50 \%$ over the stationary condition. Note also the elevation of the discharge rate during the stimulus.

The third row illustrates a $+\mathrm{Wh}$ center/ $-\mathrm{Bl}$ surround $\mathrm{X}$ cell showing little or no grating effect. The question immediately arises as to the criterion for an effect. In order to quantify this, we compiled a series of 5 histograms to the same light spot for this cell in the presence of the moving grating and also the stationary grating. Qualitatively, all 10 histograms were superimposable by eye. For 15 cells showing no obvious grating effects, the range in peak firing rate across conditions was 5 impulses/sec, and the standard deviation was 2.1 impulses/ sec. This translates into a $7 \%$ change in activity across conditions. We considered a net change in firing rate between stationary and moving conditions of $10 \%$ or better as evidence for feedback. Changes less than $10 \%$ were not easily distinguished from the random variability between histograms. The cell in Figure 2, third row, showed a net change of $6 \%$ ( 3 impulses/sec) and thus showed no effect by our criterion. The cells in rows 1 and 2 showed $86 \%$ and $50 \%$ changes, respectively. Among cells exceeding the criterion, the size of the effect ranged from $10 \%$ to $86 \%$. Small to large effects were found among all spectral cell types and among $\mathrm{X}$ and $\mathrm{Y}$ types. There were no obvious laminar differences in the magnitude or sign of the effect.

We attempted to rule out the possibility that there were long term changes in cell excitability (e.g., cell 

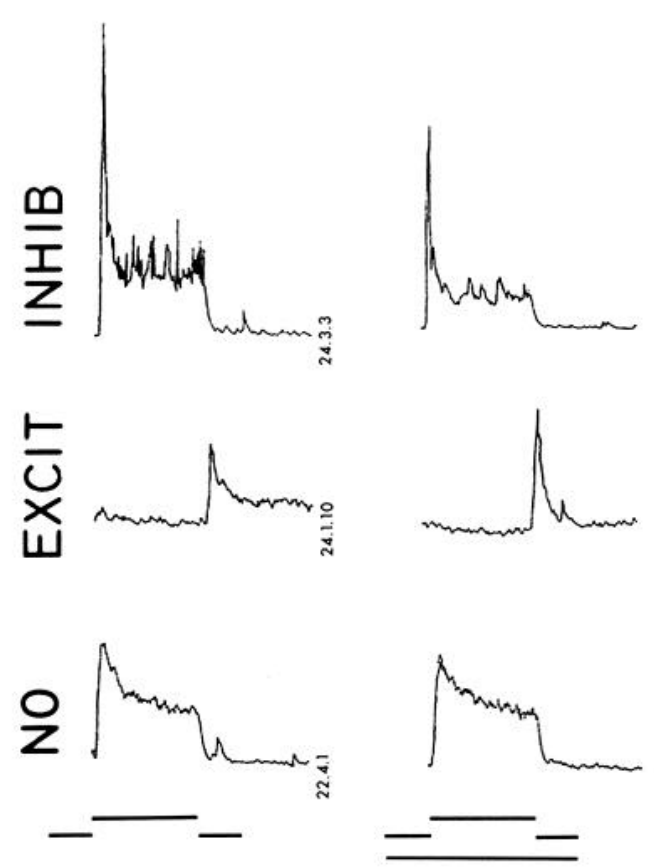
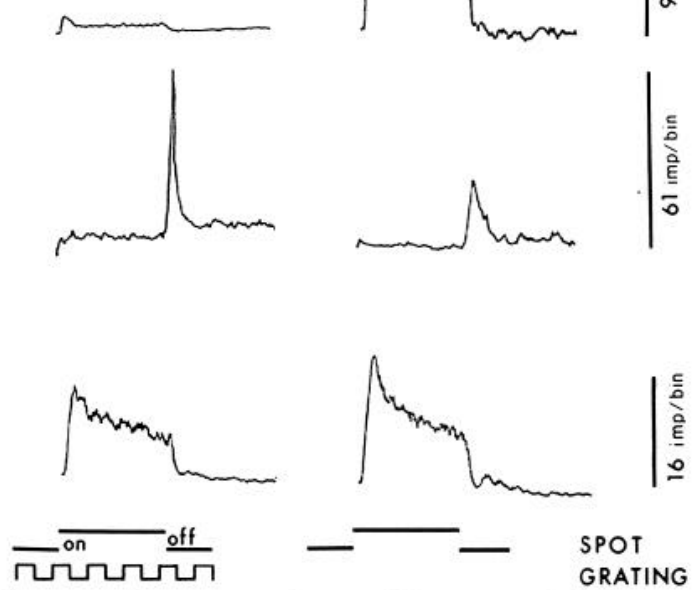

Figure 2. Corticofugal influences can be inhibitory, excitatory, or absent. Upper row, inhibitory feedback in an on-center X cell; middle row, excitatory feedback in an off-center X cell; lower row, no significant feedback in an on-center X cell. In each row: first column, responses to spot alone; second column, responses to the spot in the presence of the stationary grating; third column, responses to the spot plus moving grating; fourth column, repeat of conditions in first column. The two traces below the histograms represent photocell responses to the test flash (top) and the grating (bottom). See text for further details.

deterioration, eye movements) giving the appearance of an effect by repeated testing. The right column of Figure 2 illustrates the responses of the 3 cells to the flashing spot alone, recorded approximately $1 \mathrm{hr}$ later after all other data had been obtained. In each case, the histograms from the same cell are virtually identical. We were able to hold $53 \%$ of our cells for the entire sequence of tests. Of these, $91 \%$ showed repeatability of response rates to within $5 \%$ of the first determination. Those few cells that were nonstationary were excluded from the present analysis.

Table I shows the distribution of modulatory effects among some of the cell types that we studied. Across cell types, about $57 \%$ of all cells showed inhibitory effects; about $6 \%$ showed excitatory effects, while the remaining $37 \%$ were unaffected by our technique. Modulatory effects of the grating were found in most spectrally opponent ( 28 of 51 cells tested) as well as most broadband (11 out of 20 cells tested) units. Fifty-two percent of the X cells and all of the Y cells showed an effect. Cells with short as well as long shock latencies showed the effect. These results suggest that the function of the modulation is to change LGN cellular activity in ways not related specifically to color processing, spatial summation, or afferent conduction latency.

The origin of the modulatory effect could reside in retinal, geniculate, or cortical mechanisms or some combination of these. We have carried out a systematic series of control experiments to determine the origin. First, we recorded from intrageniculate retinal axons (see "Materials and Methods"). Of 11 putative ganglion cell axons tested, none showed any indication of a modulatory
TABLE I

Summary of feedback effects among cell types The figures in parentheses are row percentages.

\begin{tabular}{lrllr}
\hline \multicolumn{1}{c}{ LGN Cells } & Inhibitory & Excitatory & No Effect & Total \\
\hline Type & & & & \\
X on-center & $17(27 \%)$ & $2(3 \%)$ & $18(29 \%)$ & \\
X off-center & $16(25 \%)$ & $2(3 \%)$ & $8(13 \%)$ & X: 63 \\
Y on-center & $2(25 \%)$ & 0 & 0 & \\
Y off-center & $6(75 \%)$ & 0 & 0 & Y: 8 \\
Total & $41(57 \%)$ & $4(6 \%)$ & $26(37 \%)$ & 71 \\
& & & & \\
Chiasm latency (msec) & & & & \\
$1.0-1.49$ & 3 & 1 & 1 & \\
$1.5-1.99$ & 6 & 2 & 4 & \\
$2.0-2.49$ & 5 & 1 & 5 & \\
$2.5-2.99$ & 6 & 1 & 7 & \\
$3.0-3.49$ & 1 & 1 & 3 & \\
$3.5-3.99$ & 2 & 0 & 0 & \\
Total & $23(47)$ & $6(12)$ & $20(41)$ & 49 \\
\hline Retinal Axons & & & & \\
\hline Type & & & & \\
X on-center & 0 & 0 & $8(73 \%)$ & \\
X off-center & 0 & 0 & $2(18 \%)$ & X: 10 \\
Y on-center & 0 & 0 & $1(9 \%)$ & Y: 1 \\
Total & 0 & 0 & $11(100 \%)$ & 11 \\
\hline
\end{tabular}

effect (see Fig. 3 for one example). The evidence thus suggests either a geniculate or cortical origin of the modulatory effect.

If the modulation was of cortical origin, then blocking the output of the cortex should abolish the effect. In order to test this, we examined the effect of cryogenic 


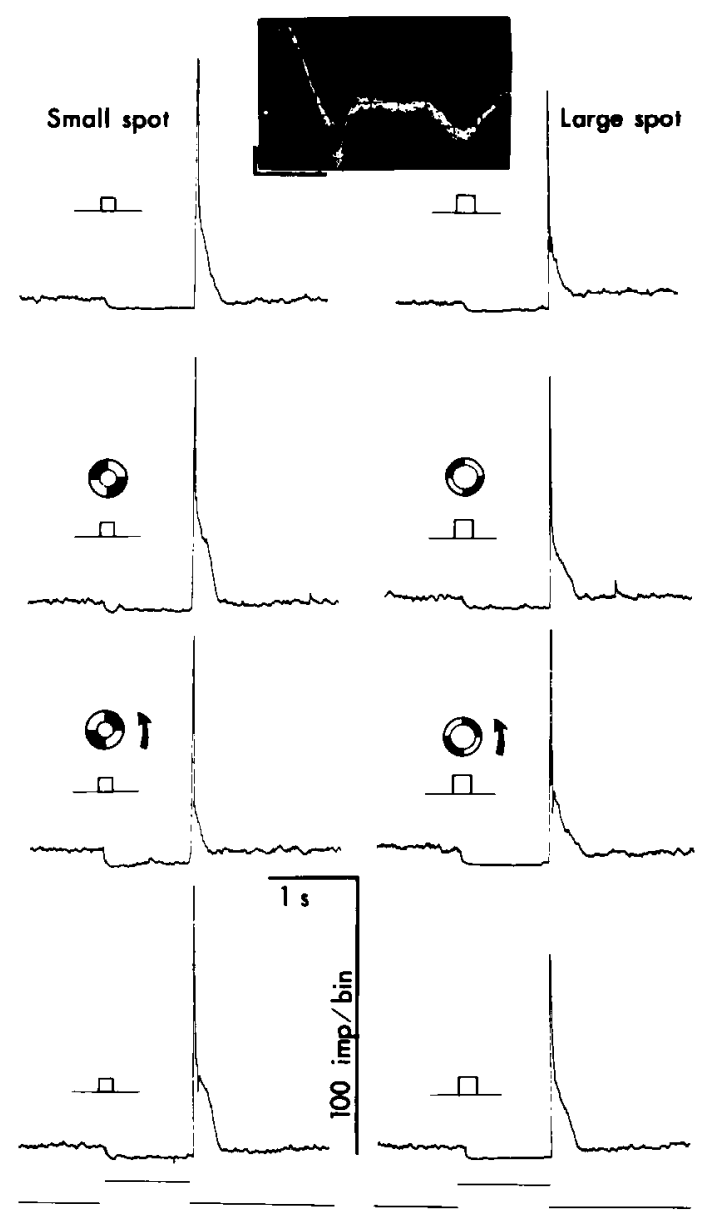

Figure 3. Responses of an intrageniculate retinal axon to the grating conditions. Inset, orthodromic action potential evoked by electrical stimulation $(100 \mu \mathrm{sec}, 600 \mu \mathrm{A})$ of the optic chiasm. Amplitude calibration $=200 \mu \mathrm{V}$; time calibration $=0.5$ msec. Shock artifact is indicated by the white dot. Note the longer latency LGN field potential at about $1.2 \mathrm{msec}$. Left column, responses to a small test spot $\left(0.1^{\circ}\right)$; right column, responses to a large spot $\left(0.8^{\circ}\right)$. Top row, flashing spot alone; second row, flashing spot plus stationary grating; third row, flashing spot plus moving grating; fourth row, repeat of first row. Calibrations: $1 \mathrm{sec}$ and 100 impulses/bin. No grating effect is observed for this axon.

blockade of striate cortex. The responses of an LGN cell to the test flash plus stationary grating were compared to those to the test flash plus moving grating before, during, and after cortical cooling to $2^{\circ} \mathrm{C}$. Figure 4 illustrates the results of these experiments for $1+G$ center/ $-\mathrm{R}$ surround $\mathrm{X}$ cell. The top row shows test flash responses in the presence of the stationary grating. The effect during cortical cooling (middle column) was a slight increase in the response over before (left column) and after (right column) responses, but the change was within the variability estimate for this cell ( \pm 4 impulses/ sec/5 repetitions). The bottom row shows that, before cortical cooling, the moving grating reduced the flash response by about $50 \%$ (left column). Cortical cooling, however, disinhibited the response, which now has a peak and sustained rate comparable to the stationary grating condition (middle column). The lower right histogram shows that rewarming the cortex recovered the precooling inhibition.
In all 18 cells with a modulatory effect which were tested, the inhibitory or excitatory modulatory effects of the moving grating were always eliminated by cortical cooling. That is, 12 cells tested whose fields lay within the cooled area which showed inhibitory effects in the warm condition were disinhibited by the cooling. Six cells showing excitatory effects were disfacilitated. Second, in $12 \mathrm{LGN}$ cells whose receptive fields lay beyond the area of visual space covered by the cooling chamber (approximately 1 to $4^{\circ}$ horizontally and from 1 to $10^{\circ}$ vertically), the modulatory effect was not reversible by cooling (see Table II). Finally, 15 cells whose fields were within the

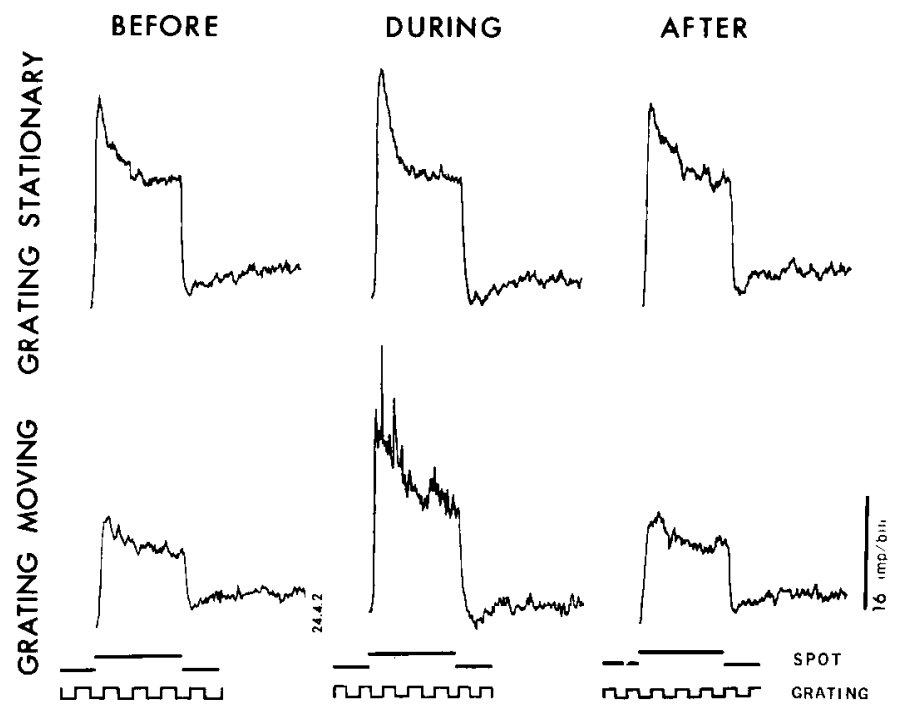

Figure 4. Cortical cooling disinhibits the inhibitory feedback in an on-center X cell. Upper row, test flash responses with the stationary grating; lower row, test flash responses with the moving grating. Left column, before cooling (cortex at $37.5^{\circ} \mathrm{C}$ ); middle column, during cooling of cortex to $2^{\circ} \mathrm{C}$; right column, after rewarming to $37.5^{\circ} \mathrm{C}$. Note that the amplitudes of the grating stationary and grating moving histograms during cooling are identical. The response to the moving grating during cooling is twice that during the warm periods.

TABLE II

Percentage of change in LGN cell activity as a result of cryogenic blockade of visual cortex for cells inside and outside of the visual area cooled

The percentage of change was calculated as the ratio of the peak responses in the moving grating condition divided by those in the stationary grating condition multiplied by 100 , and this number subtracted from 100. Negative values represent an inhibitory effect; positive values show an excitatory effect. The table includes only cells for which stationariness could be demonstrated.

\begin{tabular}{cccc}
\hline & Warm & Cool & Rewarm \\
\hline Inside & -33 & -4 & -30 \\
& -16 & 0 & -25 \\
& -50 & +2 & -52 \\
& -54 & +7 & -26 \\
& -10 & -5 & -14 \\
& +32 & -1 & +27 \\
& & & \\
Outside & -61 & -59 & -55 \\
& -41 & -48 & -43 \\
& -50 & -44 & -58 \\
& -19 & -13 & -20 \\
& -38 & -42 & -38 \\
& +29 & +42 & +27 \\
\hline
\end{tabular}


cooled area but which did not show a modulatory effect were unaffected by the cooling. This latter result rules out any nonspecific effect of axon terminal cooling on initial segment spike generation. The specificity of these results lends support to the conclusion that layer 6 cells in striate cortex were blocked by cryogenic means. However, the site at which the feedback modulated the LGN cell, whether through center or classical surround or through a peripheral zone, was not determinable from these experiments.

It was not possible to test each cell in our sample under conditions of cryogenic blockade. In cases not tested with cryogenic blockade, the modulatory effects could have originated in the geniculate (or have been relayed from the retina) rather than the cortex. For example, a "periphery effect" (McIlwain, 1964) has certain similarities to the CG feedback effects. We could not exclude this possibility positively without cortical cooling. We therefore sought to assess the prevalence and properties of such zones beyond the classical center and surround receptive field.

"Suppressive fields" have been described for cat LGN and retinal ganglion cell receptive fields (Levick et al., 1972; Enroth-Cugell and Jakiela, 1980). These regions have been shown to reduce (increase) the spontaneous activity and the response to test spots presented to the field center in on- (off-) center cells and have the same sign as the surround mechanism (Enroth-Cugell and Jakiela, 1980). This mechanism clearly can explain neither the excitatory effects that we found in on-center cells nor inhibitory effects in off-center cells (see Fig. 5) but could explain inhibitory effects in on-center cells. To assess the presence of such a field, we compared contrast sensitivity measurements to a drifting grating covering only the classical center and surround with those obtained when the grating covered the entire oscilloscope face $\left(10 \times 10^{\circ} \mathrm{arc}\right)$. If a cell had a suppressive field, its spatial tuning curve should be narrower than if it lacked such a field (e.g., see Movshon et al., 1978). None of the
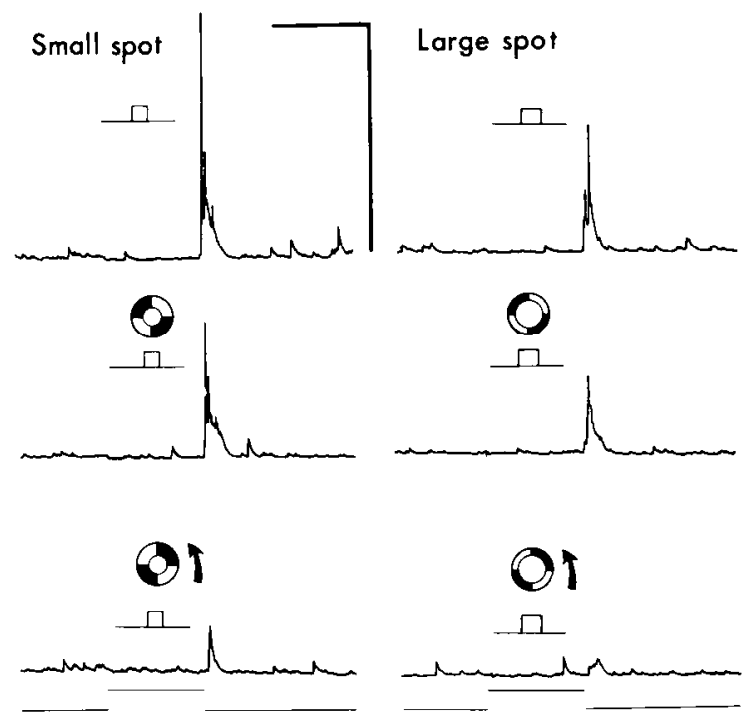

Figure 5. Responses of an LGN off-center X cell to the grating conditions. Conventions are as in Figure 3. Response calibrations: $1 \mathrm{sec}$ and 85 impulses/bin. The moving grating inhibits the off-discharge of the cell.
10 cells examined showed any differences between large and small field stimulation. Peak spatial frequency, bandwidth, and response amplitudes were unchanged for the two conditions. A more complete report of these findings will be presented elsewhere (R. T. Marrocco, J. W. McClurkin, and R. A. Young, unpublished observations).

Extra-receptive field influences also have been described recently for monkey LGN cells by Kruger (1977). The so-called "shift effect" that he describes is produced by the rapid displacement of a high contrast stimulus in regions far beyond the receptive field surround, and it is probably equivalent to the periphery effect of McIlwain (1964). We used stimulus conditions identical to those described by Kruger (1977) in cells for which a moving grating effect was demonstrated. A high contrast, square wave grating subtending $40 \mathrm{deg}^{2}$ of arc was projected onto the tangent screen. The grating was absent from a window $20^{\circ}$ of arc in diameter centered on the cell's receptive field. The responses of the LGN cell were averaged before, during, and after a rapid half-cycle shift in the grating's position. Among 37 parvocellular $(\mathrm{X})$ and 8 magnocellular $(6 \mathrm{X}, 2 \mathrm{Y})$ cells showing radial grating effects, none exhibited a shift effect (R. T. Marrocco, J. W. McClurkin, and R. A. Young, unpublished observations). That is, the grating displacement failed to elicit a response in all cells tested. Conversely, 4 parvocellular cells (X) having a shift effect did not show a radial grating effect. We conclude that the radial grating effect is not due to extra fields beyond the classical field surround.

Another mechanism of geniculate origin that could account for the modulatory effect is the direct stimulation of the cell by the radial grating. One could argue that, by underestimating the true size of the classical surround, the grating could have been stimulating the cell directly. One would guess that the effects of successive light and dark vanes would cancel over time, but this may not be the case for all cells. If some cells were mostly affected by, for example, the light vanes, then the polarity of the effect would be the same as the sign of the surround mechanism. In fact, among X cells, excitatory and inhibitory effects were found in roughly equal numbers of oncenter (off-surround) and off-center (on-surround) fields (see Table I).

In order to control further for direct rather than feedback activation of the cells by the grating, we carefully measured the spontaneous activities of $68 \mathrm{X}$ and $\mathrm{Y}$ cells in the absence of the grating and also with the grating either stationary or moving. In each case, the size of the central disk was custom-fitted to slightly exceed the surround dimensions (see "Materials and Methods"). In all $64 \mathrm{X}$ and $4 \mathrm{Y}$ cells tested, presentation of the stationary grating affected the cell's activity in the same direction as the sign of the central mechanism. This was consistent with the hypothesis that stray light was present in the central ("blank") disk and stimulated the more sensitive center. In none of the cells, however, did the moving grating produce any further change in either the rate or pattern of spontaneous discharge.

It might be objected that spontaneous activity is not sensitive enough as an indicator and that some subliminal changes in excitation or inhibition still might be present. For example, the balance between center and surround 
may have been altered. Changes in spatial antagonism would be seen more easily in responses to large, rather than small, spots. To test this notion, we have repeated many of the feedback experiments using large test spots which extended well beyond the surround in $50 \mathrm{X}$ and 2 $\mathrm{Y}$ cells. The blank central disk of the grating was chosen to be slightly larger than the test stimulus. In all cases tested, the effect was either the same magnitude or slightly less potent than that with the small central spot. More importantly, there were no significant changes between stationary and moving conditions, suggesting that the center-surround balance was unaltered. We therefore believe it unlikely that the modulation of LGN cell responsivity by the grating was due to LGN surround activation.

In summary, the results indicated that a high contrast rotary stimulus moving beyond the receptive field surround of a geniculate cell depressed the responsiveness of some cells and enhanced it in others. The effect occurred in about half of all LGN cells tested and occurs across different cell categories. The effect was due to cortical influences presumably originating in layer 6 of striate cortex.

\section{Discussion}

This report has demonstrated a novel method to study visual feedback from cortex to LGN by the use of a rotating grating. About half of all LGN cells tested were affected by this stimulus, and various control experiments argued against direct afferent activation. Of the cells affected, most were inhibited, while a small percentage were excited. We found that more $\mathrm{Y}$ cells were affected $(100 \%)$ than $\mathrm{X}$ cells $(58 \%)$. This result suggests that either the ratio of $C G$ afferents to cells is higher in magnocellular than parvocellular layers or that each afferent multiply innervates several cells. Whatever the mechanism, CG feedback appears to operate on all cell types within the magnocellular layers (e.g., types III and IV; Wiesel and Hubel, 1966). It also should be noted that our sample of $Y$ cells is small and that the percentage affected could change considerably with further testing.

Schmielau and Singer (1977) report that CG feedback in the cat visual system acts to facilitate LGN binocular interactions. They showed that eye alignment is crucial for detecting the CG influence. If this were also true for the monkey LGN, then we would not have seen a CG influence at all because we did not align the eyes (the nonstimulated eye was occluded). However, since we did not align the eyes, we cannot know whether the binocular facilitation also may be present in monkey. It should be stressed, however, that about $80 \%$ of cat LGN cells have binocular receptive fields, although the nondominant eye is often purely suppressive (e.g., Sanderson et al., 1971; Rodieck and Dreher, 1979). The corresponding number in monkey LGN cells has been reported to be about $10 \%$ for parvocellular and magnocellular cells (Marrocco and McClurkin, 1979), while Rodieck and Dreher (1979) found no binocular (X-like) parvocellular cells and $28 \%$ binocular (Y-like) magnocellular cells. Clearly, if monkey LGN cells are monocular, then interocular alignment cannot be important for retinal afferent interactions in LGN receptive fields. In terms of cortical cell binocularity, not aligning the eyes may have caused an underesti- mate of the incidence or magnitude of CG input to LGN cells.

The present results also suggested that feedback affects LGN evoked activity but not spontaneous activity. This result differs from the conclusions of Hull (1968) and Kalil and Chase (1970), who found changes in both spontaneous and evoked activity to flashing spots. Our results are concordant with the work of Baker and Malpeli (1977), although these workers found a much more subtle change in LGN responsiveness to flashing and moving stimuli in monkey LGN. We believe that the present data are highly consistent with those of Tsumoto et al. (1978) in cat. These investigators iontophoresed glutamate in the region of layer 6 cells of cat visual cortex. If the receptive fields of the simultaneously recorded LGN and cortical layer 6 cells were within $2.3^{\circ}$, the $\mathrm{CG}$ action was excitatory. If the centers were beyond $2.3^{\circ}$, an inhibitory effect was found. No effect was seen with separations greater than $3.1^{\circ}$. In many cases, our grating lacked a central region of about $2^{\circ}$ and we therefore could not assess a possible excitatory region. However, the vanes of the grating should activate the inhibitory feedback as found by Tsumoto et al. (1978), and this is precisely what was observed.

Using a radial grating stimulus paradigm, Fukuda and Stone (1976) obtained results from cat LGN showing that a radially moving grating centered on the receptive field produces a marked change (inhibition on X cells, excitation in $Y$ cells) in the cell's spontaneous rate. They attributed this to intrageniculate inhibition and showed that the effect was present with dichoptic stimulation. We found no changes in spontaneous activity and favor a CG feedback interpretation for our data. Although their conclusions differ markedly from ours, there are no compelling reasons in their data to rule out contributions from CG feedback as well as intrageniculate inhibition.

The synaptic locus of the GC effect is uncertain. Anatomical evidence suggests that CG fibers usually contact interneurons, although they occasionally end on relay cell dendrites (Guillery, 1967; Guillery and Colonnier, 1970). A direct axodendritic junction would require at least two different types of CG fiber transmitters to account for inhibitory and excitatory effects, according to generally accepted rules of neuropharmacology. Alternatively, there may be several kinds of subsynaptic receptor molecules and a single transmitter. Further research may help decide between some of these alternatives.

The ability of a central visual structure to control its afferent input through feedback mechanisms is widespread in the central nervous system of many species, but with few exceptions, its physiology and function are poorly understood. We have shown that area 17 affects the ability of macaque LGN cells to transmit visual information but have given no indication of what aspects of information carried by LGN cells are affected. We will report on some of the functions of the CG pathway in a subsequent paper (J. W. McClurkin, R. T. Marrocco, and R. A. Young, manuscript in preparation).

\section{References}

Baker, F. H., and J. G. Malpeli (1977) Effects of cryogenic blockade of visual cortex on responses of lateral geniculate neurons in the monkey. Exp. Brain Res. 29: 433-444. 
Bishop, P. O., W. Burke, and R. Davis (1962) Single-unit recording from antidromically activated optic radiation neurons. J. Physiol. (Lond.) 162: 432-450.

Cowan, W. M., and T. P. S. Powell (1963) Centrifugal fibers in the avian visual system. Proc. R. Soc. Lond. (Biol.) 158: 232-252.

Enroth-Cugell, C., and H. G. Jakiela (1980) Suppression of cat retinal ganglion cell responses by moving patterns. J. Physiol. (Lond.) 302: 49-72.

Enroth-Cugell, C., and J. G. Robson (1966) The contrast sensitivity of retinal ganglion cells in the cat. J. Physiol. (Lond.) 187: 517-552.

Fukuda, Y., and J. Stone (1976) Evidence of differential inhibitory influences on X- and Y-type relay cells in the cat's lateral geniculate nucleus. Brain Res. 113: 118-196.

Geisert, E. E., A. Langsetmo, and P. D. Spear (1981) Influence of the corticogeniculate fatinway on response properties of cat lateral geniculate neurons. Brain Res. 208: 409-415.

Gilbert, C. D. (1977) Laminar differences in receptive field properties of cells in cat primary visual cortex. J. Physiol. (Lond.) 268: 391-421.

Gilbert, C. D., and J. P. Kelly (1975) The projection of cells in different layers of the cat's visual cortex. J. Comp. Neurol. 163: 81-106.

Guillery, R. W. (1967) Patterns of fiber degeneration in the dorsal lateral geniculate nucleus of the cat following lesions in the visual cortex. J. Comp. Neurol. 130: 197-222.

Guillery, R. W., and M. Colonnier (1970) Synaptic patterns in the dorsal lateral geniculate nucleus of the monkey. Z. Zellforsch. Mikrosk. Anat. 103: 90-108.

Harvey, A. H. (1978) Characteristics of corticothalamic neurons in area 17 of the cat. Neurosci. Lett. 7: 177-181.

Hendrickson, A. E., J. R. Wilson, and M. P. Ogren (1978) The neuroanatomical organization of pathways between dorsal lateral geniculate nucleus and visual cortex in Old World and New World monkeys. J. Comp. Neurol. 182: 123-136.

Holländer, D., and A. Martinez-Milan (1975) Autoradiographic evidence for a topographically organized projection from the striate cortex to the lateral geniculate nucleus in the rhesus monkey (Macaca mulatta). Brain Res. 100: 407-411.

Hubel, D. H., and T. N. Wiesel (1968) Receptive fields and functional architecture of monkey striate cortex. J. Physiol. (Lond.) 195: 215-243.

Hull, E. M. (1968) Corticofugal influences in the macaque lateral geniculate nucleus. Vision Res. 8: 1285-1298.

Kalil, R., and M. Chase (1970) Corticofugal influence on activity of lateral geniculate neurons in the cat. J. Neurophysiol. 33: 459-474.

Kruger, J. (1977) The shift-effect in the lateral geniculate body of the rhesus monkey. Exp. Brain Res. 29: 387-392.

Levick, W. R., B. G. Cleland, and M. W. Dubin (1972) Lateral geniculate neurons in cat: Retinal inputs and physiology.
Invest. Ophthalmol. Vis. Sci. 11: 302-311.

Lund, J. S., R. D. Lund, A. E. Hendrickson, A. H. Bunt, and A. F. Fuchs (1975) The origin of efferent pathways from the primary visual cortex, area 17 , of the macaque monkey as shown by retrograde transport of horseradish peroxidase. J. Comp. Neurol. 164: 287-304.

Marrocco, R. T. (1976) Sustained and transient cells in monkey lateral geniculate nucleus: Conduction velocities and response properties. J. Neurophysiol. 39: 340-353.

Marrocco, R. T., and J. W. McClurkin (1979) Binocular interaction in the monkey lateral geniculate nucleus. Brain Res. 168: 633-637.

Marrocco, R. T., J. W. McClurkin, and Z. H. Farooqi (1979) Modulation of LGN cell sensitivity by visual activation of the corticogeniculate feedback pathway. Soc. Neurosci. Abstr. 5: 795.

Mcllwain, J. T. (1964) Receptive fields of optic tract axons and lateral geniculate cells: Peripheral extent and barbiturate sensitivity. J. Neurophysiol. 27: 1154-1173.

Movshon, J. A., I. D. Thompson, and D. J. Tolhurst (1978) Spatial summation in the receptive fields of simple cells in the cat's striate cortex. J. Physiol. (Lond.) 283: 53-77.

Richard, D., Y. Gioanni, A. Kitsikis, and P. Buser (1975) A study of geniculate unit activity during cryogenic blockage of the primary visual cortex in the cat. Exp. Brain Res. 22: 235-242.

Rodieck, R. W., and B. Dreher (1979) Visual suppression from nondominant eye in the lateral geniculate nucleus: A comparison of cat and monkey. Exp. Brain Res. 35: 465-477.

Sanderson, K. J., P. O. Bishop, and I. Darian-Smith (1971) The properties of the binocular receptive fields of lateral geniculate neurons. Exp. Brain Res, 13: 178-207.

Schiller, P. H., B. L. Finlay, and S. F. Volman (1976) Quantitative studies of single cell properties in monkey striate cortex. I. Spatio-temporal organization of receptive fields. J. Neurophysiol. 39: 1288-1319.

Schmielau, F., and W. Singer (1977) The role of visual cortex for binocular interactions in the cat lateral geniculate nucleus. Brain Res. 120: 354-361.

Spoendlin, H. (1966) The organization of the cochlear receptor. In Advances in Oto-Rhino-Laryngology, H. Spoendlin, ed., pp. 68-69, S. Karger, Basel, Switzerland.

Tsumoto, T., O. D. Creutzfeldt, and C. R. Legendy (1978) Functional organization of the corticofugal system from visual cortex to lateral geniculate nucleus in the cat. Exp. Brain Res. 32: 345-364.

Vastola, E. (1967) Steady state effects of visual cortex on geniculate cells. Vision Res. 7: 599-609.

Wiesel, T. N., and D. H. Hubel (1966) Spatial and chromatic interactions in the lateral geniculate body of the rhesus monkey. J. Neurophysiol. 29: 1115-1156. 